\title{
A RIQUEZA FORMAL NA POESIA DE ANTONIO BRASILEIRO
}

\author{
Bolsista Fabrício Lima Oliveira, Graduando em Letras Vernáculas, Universidade \\ Estadual de Feira de Santana, e-mail: fabricio16.mahalo@ gmail.com. \\ Orientador Antonio Gabriel Evangelista De Souza, Departamento de Letras e Artes, \\ Universidade Estadual de Feira de Santana, e-mail: profantoniogabriel@gmail.com
}

PALAVRAS-CHAVE: Literatura; Imagens; Lírica.

\section{INTRODUÇÃO}

O poeta Antonio Brasileiro é, reconhecidamente, um dos mais consistentes poetas brasileiros, na contemporaneidade. A consistência de sua obra evidencia-se, entre outras coisas, pelo rigor formal e pela utilização e domínio de uma gama muito variada de recursos técnicos, ajustados de forma singular à composição de cada um de seus poemas. Trata-se, portanto, de um poeta fundamental, situado como nome de referência para uma geração importante de poetas, surgida em Feira de Santana, a partir de 1972, com a criação, pelo próprio Antonio Brasileiro, da Revista Hera (1972 - 2005) que publicou 20 números e que hoje se situa como um marco histórico da poesia brasileira, na atualidade. Este trabalho de pesquisa se justifica como mais uma contribuição no sentido de realçar a importância da riqueza formal de um poeta que, ao longo das últimas quatro décadas, tem inspirado gerações de poetas, na Bahia e, especialmente, em Feira de Santana.

Antonio Brasileiro (Antonio Brasileiro Borges), poeta, ensaísta, artista plástico e professor, nasceu em 15 de Junho de 1944 em Matas do Orobó, Bahia. Reside atualmente em Feira de Santana. Eleito em 08/06/2009 para a Academia de Letras da Bahia, é o primeiro escritor residente no interior do estado a assumir uma Cadeira na referida Academia, ocupando a cadeira de Zélia Gattai. Antonio Brasileiro é um dos mais consistentes poetas brasileiros, na contemporaneidade. Sua poesia é instigante e evidencia-se, entre outras coisas, pelo rigor formal e pela utilização e domínio de uma gama muito variada de recursos técnicos.

Na década de 1960 - entre os quinze e vinte e cinco anos - o poeta, já residente em Salvador, vive uma vida intensa: entra para a Universidade (Ciências Sociais, UFBA), passa a estudar no Seminário de Música, além disso, começa a pintar, publica seus primeiros livros, cria as Edições Cordel (Revistas Serial e Cordel). Reside por algum tempo no Rio de Janeiro e em Belo Horizonte (1966/67) e têm poemas publicados na Revista Civilização Brasileira. No início de 1971, passa a morar em Feira de Santana, onde cria a revista Hera (1972 - 2005) em parceria com os alunos seus do Colégio Estadual de Feira de Santana, a exemplo de Roberval Pereyr, Washington Queiroz e Wilson Pereira de Jesus. Hera, que em seus três primeiros números era uma revista de contos, a partir do número 4 passou a publicar apenas poesia (e, como tal, contando, a partir daí, com a participação de nomes como, entre outros, Juraci Dórea, Iderval Miranda, Luís Valverde, Luis Pimentel, Edmundo Carôso (Edmundo) e Carlos Pitta (Piter), Trazíbulo Henqique Pardo Casas, Rubens Alves Pereira, Assis Freitas Filho, Juraciara Lima, além dos três cofundadores acima citados), engendrou, sob a 
coordenação inicial de Antonio Brasileiro, uma marcante movimentação literáriocultural na Bahia, com significativa repercussão nacional. Alguns anos depois (1980), sai pela Editora Civilização Brasileira o primeiro livro de poesia de Antonio Brasileiro em edição nacional, intitulado Os três movimentos da sonata. Em 1992, Brasileiro conclui seu Mestrado em Letras pela UFBA, e liga-se, como professor, à Universidade Estadual de Feira de Santana-UEFS (1993). Anos depois, conclui Doutorado em Literatura Comparada (UFMG, 1999). Antonio Brasileiro, como pintor, está entre os da chamada Geração 70 de artistas plásticos da Bahia. Com quase 30 livros publicados, destacam-se entre eles: Caronte (1995, romance), Antologia poética (1996), A estética da sinceridade (2000, ensaios), Da inutilidade da poesia (2002, ensaio), Poemas reunidos (2005), Dedal de areia (2006, poesia), Desta varanda( ), Longes terras ( ) e Lisboa 1935 ( ).

O poeta Antonio Brasileiro apresenta na sua obra uma apurada reflexão líricofilosófica. Sua multifacetada poesia retrata, de muitas maneiras e em muitas dimensões, a instabilidade e a fragilidade da condição humana. Para dar conta de tudo isso, o poeta evidencia o domínio de muitas áreas de conhecimento e a capacidade de encontrar soluções formais para as mais diversas situações existenciais encenadas em seus poemas. Neste sentido, não hesita em lançar mão, por exemplo, do mais puro lirismo, ou, ao contrário, do exagero cômico, do grotesco, da ironia, da sátira e do desconcertante humor que lhe é característico, muitas vezes obtido pela rara capacidade de utilização do paradoxo, que põe em cheque a mera racionalidade, gerando choque e surpresa. Tudo isso sem perder jamais de vista a dimensão estética da linguagem, evidenciada através da utilização (e da combinação) sempre oportuna e surpreendente do ritmo, da imagem e da musicalidade.

\section{MATERIAL E MÉTODOS OU METODOLOGIA (ou equivalente)}

O presente trabalho foi realizado, principalmente, através de pesquisa bibliográfica - diversos livros de poemas de Antonio Brasileiro e textos teóricos que serviram de base para a abordagem crítica do autor. Foram realizadas, além disso, entrevistas com o autor e com outros poetas feirenses, ligados à Revista Hera, que acompanharam e conhecem a obra de Antonio Brasileiro, desde o início do movimento poético ligado à trajetória da referida revista. Por conseguinte, esta pesquisa teve, também, como propósito buscar sua consistência a qual se evidencia, entre outras coisas, pelo rigor formal, pela construção, baseando-nos no livro As origens da forma na arte (1967), de Herbert Read. Por outro lado, evidenciou-se ainda a utilização e domínio de uma gama muito variada de recursos técnicos. Destacaram-se e analisaram-se também poemas do livro Poemas Reunidos, de Antonio Brasileiro, para evidenciar a riqueza formal, o ritmo e a musicalidade, usando como apoios os livros A essência da poesia (1972), de T.S. ELIOT, Poética e Tópicos I, II, III e IV (2013), de Aristóteles, Abc da Literatura (1961), de Ezra Pound, A unidade primordial da lírica moderna (2012), de Roberval Pereyr, Papéis de poesia (2014), de Antonio Carlos Secchin, Na Madrugada das Formas Poéticas (1982), de Segismundo Spina e O arco e a lira (1955), de Octavio Paz. Para além disso, esta proposta situa-se numa visão educacional focada, entre diversos caminhos, para a leitura e o trabalho com poemas na sala de aula, mostrando, desse modo, a riqueza formal na poesia do poeta Brasileiro. Sendo assim, mostrou-se e discutiu-se métodos de trabalho com a poesia, como elemento importante da literatura popular. Dessa forma, apresentou-se que é possível trabalhar a riqueza do poema na sala de aula sem deixar de lado o caráter de alegria e criatividade, criando, assim, possibilidades para o diálogo com o poema e outras artes. 


\section{RESULTADOS E/OU DISCUSSÃO (ou Análise e discussão dos resultados)}

Conhecimento da poesia lírica de Antonio Brasileiro, no que se refere ao seu rigor formal, manifestado na sua capacidade de síntese e na utilização de uma gama muito variada de recursos técnicos em diversos poemas do autor. Através desta pesquisa, conseguiu-se a percepção de que, nos poemas de Antonio Brasileiro, a natureza assume o lugar do homem (o sujeito poético) que com ela se funde, de forma dinâmica, hermética e intensamente lírica. A poesia de Brasileiro preserva, de forma enfática, os traços de uma linguagem primordial, em que sujeito e objeto (no caso, homem e natureza) se fundem, na realização daquilo que Emil Staiger, no livro Conceitos fundamentais da poética, chama de "um-no-outro", expressão que usa para definir o estado lírico por excelência. Assim, a relação do homem com a sua origem (a natureza) é tão pura e tão plena, que a natureza, agora humanizada, toma volta o que o poeta dela absorveu. Segundo Octavio Paz, ninguém pode escapar da crença no poder mágico das palavras. A poesia de Antonio Brasileiro instaura a magia e o poder da linguagem em perspectivas e dimensões diferentes. Muitas vezes, de forma nua e crua. Portanto, chegou-se a este resultado: Brasileiro evidencia um lirismo meditativo, em que a evocação da natureza ("aquela nuvem"), articula leveza de linguagem e profundidade filosófica; revelando-se senhor de uma poesia reflexiva e filosófica, que não para de ir em busca dos aspectos obscuros de nossos pequenos e grandes problemas existenciais e desmascara as aparências falsas da vida que não dão paz ao leitor e ao poeta.

\section{CONSIDERAÇÕES FINAIS (ou Conclusão)}

Dessa forma, reafirma-se que a poesia de Antonio Brasileiro é bem traçada, filosófica, que requer muita atenção, e, muitas das vezes, como se fosse uma canção, a repetição de algumas palavras surge para enaltecer, para tornar o poema magnifico, ou, até mesmo, para dar a sensação de calmaria aos os efeitos. Brasileiro, em seus poemas, realiza uma poesia lapidada, uma poesia que mostra estética do escrever e reescrever. 


\section{REFERÊNCIAS}

BRASILEIRO, Antonio. Poemas Reunidos. Salvador, Secretaria da Cultura e Turismo, FUNCEB, 2005.

BRASILEIRO, Antonio al. Hera 1972 - 2005. Ed. Fac-similar, Salvador, Fundação Pedro Calmon; Feira de Santana, UEFS Editora 2010.

BRASILEIRO, Antonio. Da inutilidade da poesia. Feira de Santana, UEFS Editora / 7 Letras.

CANDIDO, Antonio. Presença da Literatura Brasileira I. São Paulo, Difusão Européia do Livro, 1973.

MAY, Rollo. A coragem de criar. Rio de Janeiro, Nova Fronteira, 1982.

PAZ, Octavio. O Arco e a Lira. Rio de Janeiro: Nova Fronteira, 1982.

PEREYR, Roberval. A unidade primordial da lírica moderna. Feira de Santana, UEFS, 2000.

PEREYR, Roberval. Mirantes. Rio de Janeiro, 7 Letras, 2012.

SECCHIN, Antonio. Papéis de Poesia. Goiânia, Martelo, 2014.

SPINA, Segismundo. Na Madrugada das Formas Poéticas. São Paulo, Editora Ática, 1982.

POUND, Ezra. Abc da Literatura. São Paulo, Editora Cultrix, 1961.

HUIZINGA, Johan. Homo Ludens. Editora da Universidade de São Paulo, 1971.

READ, Herbert. As origens da forma na arte. Rio de Janeiro, Zahar Editores, 1967. 